
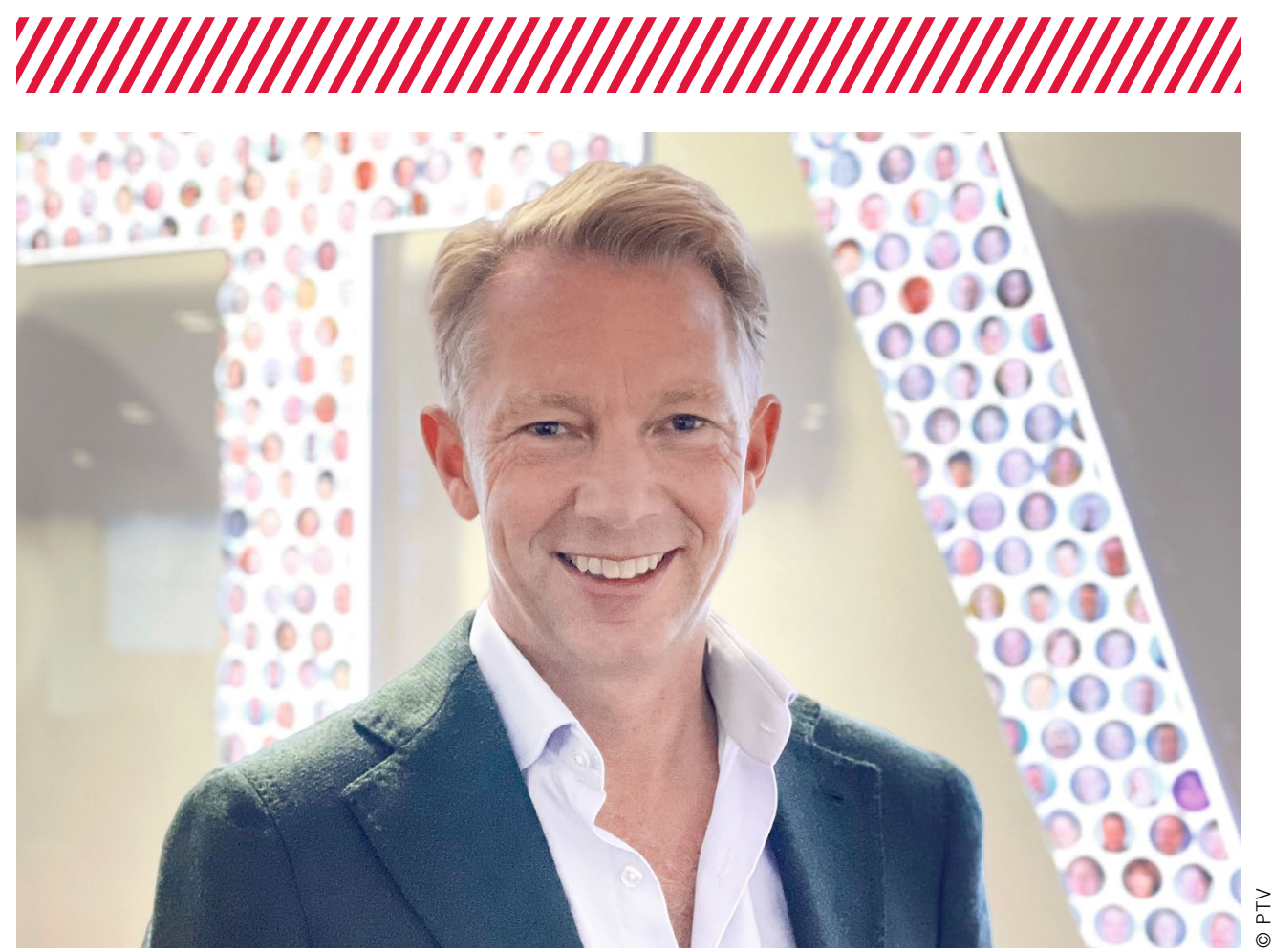

Christian U. Haas

CEO der PTV Group

\title{
Autonome Fahrzeuge - Belastungsprobe für die städtische Verkehrsinfrastruktur?
}

Der Traum vom autonomen Fahren - zahlreiche Player wie die US-Techriesen Waymo, Cruise, Tesla und Co. arbeiten daran, ihn zu verwirklichen. Durchsetzen werden sich die autonomen Fahrzeuge (Autonomous Vehicles, AV) aber wohl nur langsam - vor allem im urbanen Raum. Die Forschung geht davon aus, dass es bis weit ins 21. Jahrhundert hinein einen Mischverkehr aus konventionellen und selbstfahrenden Autos geben wird.

Aus Analysen und Forschungsprojekten wie etwa dem EUgeförderten Projekt Coexist lassen sich schon heute Rückschlüsse auf die Fahrweise der AVs ziehen. So ist davon auszugehen, dass Roboterfahrzeuge in der Anfangsphase besonders vorsichtig fahren werden. Um die größtmögliche Sicherheit zu gewährleisten, werden sie beispielsweise größere Abstände und genauer als menschliche Fahrer Geschwindigkeitsbegrenzungen einhalten. Dies kann - bei gleichbleibender Belastung der Straßen - dazu führen, dass die heutige Verkehrsinfrastruktur in Städten an ihre Belastungsgrenze gerät. In einem Beispielmodell des Kölner Univiertels konnten wir zeigen, dass sich in einem Szenario, in dem vorsichtige autonome Fahrzeuge genau die Hälfte des Verkehrs ausmachen, die Anzahl der Stopps aller Fahrzeuge im Stadtverkehr um bis zu 80 \% erhöht. Die Verlustzeit im Stau nimmt um 29 \% zu.

Mit ihrer zunehmenden Verbreitung ist davon auszugehen, dass autonome Fahrzeuge sich auch in Städten zu Gruppen, sogenannten Platoons, zusammenschließen und damit deutlich platzökonomischer und effizienter fahren.

Um der Mehrbelastung für Infrastruktur und Verkehr in der Übergangszeit entgegenzuwirken, werden Kommunen zeitnah Lösungen eruieren müssen. Dazu gehören primär solche im Bereich der Konnektivität: etwa Kreuzungen und Ampeln, die über Sensoren mit den AVs kommunizieren, sodass diese ihr Fahrverhalten anpassen können. Denkbar wäre auch eine räumliche Trennung von autonomen und manuellen Fahrzeugen, etwa durch die Freigabe von Busspuren für AVs.

Damit AVs nicht zu einem zusätzlichen Flächenverbrauch und Mehrverkehr führen, müssen sie als Teil eines ganzheitlichen Mobilitätssystems gedacht werden. Es gilt, ihren Betrieb effizient zu gestalten, die Fahrzeuge gemeinschaftlich zu nutzen und in den öffentlichen Verkehr zu integrieren. Gerade einmal $7 \%$ der heutigen Fahrzeuge wären ausreichend, wenn autonome Shared Services in Ergänzung zum öffentlichen Verkehr nutzbar wären. Zu diesem Schluss kam eine Simulationsstudie, die PTV für die Stadt Oslo durchgeführt hat.

Schon heute ein Verständnis über die Auswirkungen von autonomen Fahrzeugen zu entwickeln, ist der Schlüssel dazu, die richtigen Rahmenbedingungen zu schaffen. Nur so lässt sich ihr volles Potenzial für eine nachhaltige Mobilität der Zukunft nutzen. 